\title{
Eco-biosociocultural H5N1 disease model in Egypt
}

\author{
S. L. Wilson \& N. Oushy \\ Department of Health Science, New Mexico State University, USA
}

\begin{abstract}
This paper explores environmental and behavioral interactions that facilitate human exposure to the highly pathogenic avian influenza (HPAI) H5N1/A virus (termed bird flu or H5N1 throughout this document) in Egypt. The approach used in this research integrates public health and anthropological methods to assess environmental and behavioral interactions that facilitate human exposure to bird flu. Four key elements of the H5N1 eco-biosociocultural model were identified: (1) the subsidized natural environment; (2) the built environment; (3) the socio-political and economic environment; and, (4) the cultural environment. Analysis of these elements resulted in development of an eco-biosociocultural disease model for H5N1 that addresses health disparities by incorporating the built and subsidized natural environments integrated with associated cultural beliefs, knowledge, and behaviors. Our results suggest that the disparate incidence and mortality pattern of H5N1 in Egypt is likely affected by increased exposure opportunities among women and children resulting from lack of knowledge, traditional daily activities, poultry practices, and child-rearing activities. Despite community based health education efforts, knowledge about poultry diseases and H5N1 transmission are not well understood among Egyptian women. In the absence of a perceived immediate bird flu threat, this research suggests that women tend to maintain traditional behaviors. The H5N1 epidemiologic footprint in Egypt differs from other countries, but the lessons learned provide a basis for health education action that may be transferable to other venues.
\end{abstract}

Keywords: ecology and health, social determinants of health, Bird Flu, Egypt, H5N1, ethnography, built environment, subsidized natural environment, health disparities, eco-biosociocultural, avian influenza. 


\section{Introduction and need}

This research explores environmental and behavioral interactions that facilitate human exposure to the highly pathogenic avian influenza (AI) or HPAI H5N1 virus (termed bird flu or H5N1 throughout this document) in Egypt. Bird flu is considered a serious health threat worldwide and is a quarantinable communicable disease with a geographic range that includes Asia, Southeast Asia, Europe, the Indian subcontinent, and Africa [1]. Humans contract H5N1 by through primary or incidental (secondary) direct exposure, i.e., via inhalation of airborne effluents; ingestion of undercooked, infected meat; or by contact with excretions (e.g., saliva, feces, and contaminated feathers) [1]. Findings suggest that the virus has a much wider spectrum than originally thought; making it potentially more problematic than anticipated should it develop the capability to transfer easily from human-to-human [2]. As of March 2011, Egypt ranks second in the world in number of confirmed human H5N1 cases (behind Indonesia) and ranks third highest worldwide in total deaths (behind Indonesia and Viet Nam) [1].

Two main factors indicate the importance of addressing the human ecology of bird flu in Egypt from a holistic perspective: the epidemiologic footprint of bird flu in Egypt and a lack of behavioral data surrounding the disease. First, the epidemiological footprint of reported cases of human H5N1 in Egypt presents a distinct pattern disproportionately affecting young adult women and small children - a pattern different from that seen in other countries [1,3-5]. No attempt was made to estimate the effects of underreporting. Of a total of 144 cases of Egyptian bird flu between 2006 and 25 March 2011, 44 (30.6\%) died [1]. Most deaths $(\mathrm{N}=36,81.8 \%)$ occurred among females. Women aged 15-44 years ( $\mathrm{N}=33$ deaths) were most likely to die from the disease, accounting for $91.6 \%$ of female deaths [1]. Children of both sexes (ages birth to 14 years) contracted the disease slightly less often than adults $(\mathrm{N}=70$ or $48.6 \%$ of all cases); however, children were more likely to recover than adults ( $\mathrm{N}=65,92.8 \%$ recovery among children compared to $\mathrm{N}=21,35.0 \%$ recovery among adults) [1].

The second main factor is that, to date, no studies have addressed specific behaviors or traditional cultural practices that affect exposure, though several have identified human behavior as a factor in the disease [1, 5]. Demonstrated need suggests developing greater insight into environmental milieu affecting the presence of disease. Exposure to poultry or infected poultry account for almost all cases (a few case sources are unknown) and no cases were attributed to wild birds exposure [1]. Therefore, analysis of the Egyptian human bird flu pattern indicates a need to consider the local epidemiologic footprint when developing policy and public health actions.

\section{Methods}

The approach used in this research integrates public health and anthropological methods to assess environmental and behavioral interactions that facilitate human exposure to bird flu [6-11]. Our approach incorporated a holistic, 
bio-sociocultural ecological approach using progressive contextualization among the abiotic, biotic, and cultural environmental components [6, 10]. Researchers worked under the auspices of National Council for Childhood and Motherhood (NCCM) while in Egypt. The Institutional Review Board (IRB) at New Mexico State University reviewed and approved the research protocol, and all interview study participants signed an informed consent.

General knowledge, photographic data, observations, and personal journals based on extended participant observation and long-term social relationships (between 1989 and 2008), provided basic ethnographic background data, which were analyzed using traditional ethnographic methods [12, 13]. A grounded theory analysis [14] identified potential ecological and social determinants of health associated with bird flu. General inductive analysis established links between objectives and findings to develop a model regarding underlying structure or experiences or processes evident from the text data [15]. Cross verification triangulated interview data with nonreactive data.

A purposive sample of eight households in a rural village north of Aswan was selected for in-depth interviews during June 2008. In-depth interviews lasted 30 minutes to one hour each, followed by village and household tours. Each interviewee was female, maintained a small poultry flock, and had small children in and around the household. Researchers conducted each interview in the home of the interviewee in their native language (Arabic). A social worker from the Ministry of Health and Population (MOH-Aswan), served as an interview guide, suggested interviewees, and provided entrée to the local community. A second key informant from the Ministry of Agriculture assisted in interviews and Arabic translation. To ensure the validity of paraphrases, an independent translator assisted during household interviews. Interviews were recorded and transcribed. In addition to interviewee households, researchers visited numerous other households and villages to assess poultry practices and venues.

\section{Results}

\subsection{Study community - the context}

The principal study community was a rural village just north of Aswan, Egypt, with no direct access to the River Nile. Community development resulted from chain migration to an unpopulated area, where people subsequently built extended family housing and shops. No demographic figures are available for the village. A two-lane, paved road runs north and south through the village and other paved roads connect with the main road as one approaches Aswan to the south. Unpaved, dirt roads lead to housing areas that have branched off the main artery. Although designated as rural, the village closely resembles a chain periurban type (CPU) community, i.e., it is "geographically on an urban fringe, appears to be derived primarily from chain migration, and represents a 
reconstituted institutional context" [16, p.8]. Although specific demographic data are not available for the village, the following represents rural, Upper Egypt [17].

- Most women are illiterate (62.5\%) with a median education level of 0.3 years.

- Most people are poor: $72.8 \%$ in the two lowest quintiles and $42.7 \%$ in the lowest quintile.

- $\quad$ Most people have access to improved drinking water sources $(93.5 \%)$.

- A small number of households (8.4\%) pipe sewerage to a canal, groundwater, or have no toilet facility.

The following description typifies a common daily street scene in the village. Two-storied, mud brick buildings with brightly painted doors line the street where most doors are closed and windows are tightly shuttered. A few old cars and trucks are parked, while workers go about their daily chores. Men sit on a doorstep in front of a house talking. Most women are inside their homes, though a few venture out to purchase milk or vegetables from vendors who frequent the street with their donkey driven carts. Dressed in a traditional long dress or galabea, a barefoot young woman sips tea in her doorway, watching activities on the road. A young boy carries a small goat over to the shade by his front door. Children, some with sandals, others barefoot, ride bicycles, talk with each other, or roll an old tire down the street while laughing and chasing one another. In the shade, a water buffalo lounges lazily, while a rooster struts across the street to search for food scraps, and goats pick at tin cans and paper litter strewn about the street. Brightly colored baby clothes hang to dry on lines strung across balconies. Behind tightly closed doors lie living rooms, kitchens, and sleeping quarters and often a shared courtyard. Over the hum of human voices, poultry cluck from cages in secluded enclosures or from rooftop cages.

\subsection{Ecological analysis}

The need to consider the synergistic interaction of the avian, virus, and human environments at various levels of geography complicates evaluation of the H5N1 health and ecology system. Initially, Egypt appears largely unsuitable for H5N1 sustainability; however, the densely populated green zone along the Nile River valley and delta identify likely areas for H5N1 survival [18]. The green zone provides ample year-round habitat for large flocks of wild aquatic birds, supplemented by hundreds of thousands during winter months, many of which may shed viruses that contaminate the natural environment.

Our research identified four main recurring and overlapping environmental contexts that contribute to the H5N1 eco-biosociocultural system: (1) the natural environment; (2) the built environment; (3) the socio-political /economic environment; and, (4) the cultural environment. Each interacts synergistically with the others in complex ways to facilitate virus econiches and, ultimately, disease exposure routes and occurrence. A microenvironment conducive to virus survival results, from which domestic birds (frequently) and humans (sporadically, but, so far with reasonable consistency) become infected in Egypt. Figure 1 represents main themes identified and interactions in an ecobiosociocultural H5N1 model for Egypt. 


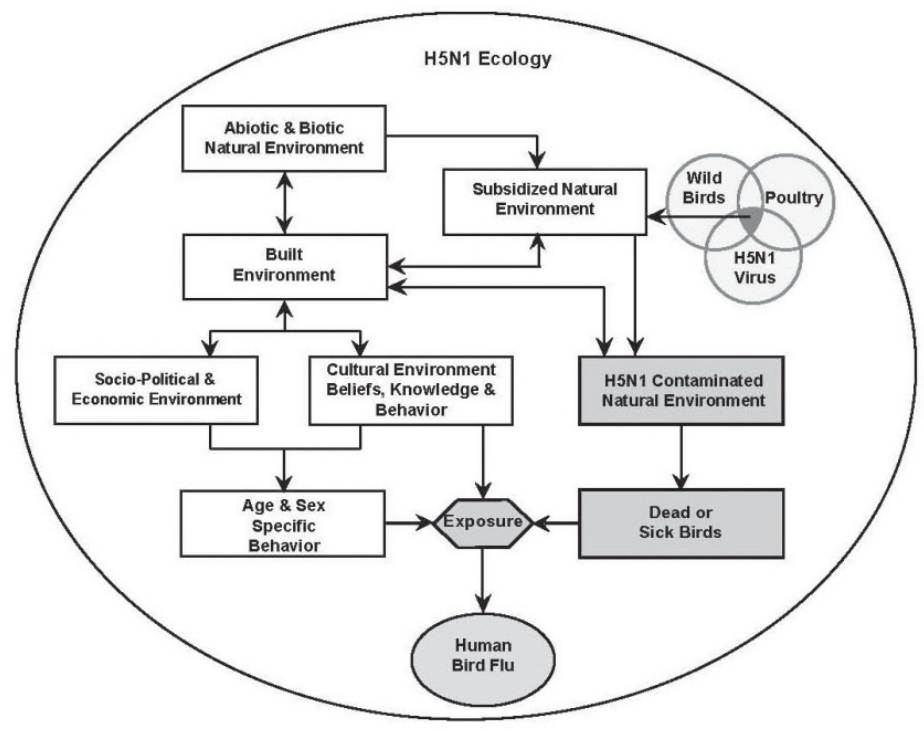

Figure 1: $\quad$ Eco-biosociocultural model of H5N1.

\section{Discussion}

\subsubsection{The subsidized natural environment}

The relationship between people and the $\mathrm{H} 5 \mathrm{~N} 1$ contaminated natural environment, especially the river and canals in rural areas, emerged as a recurring theme from analysis of field notes, literature, and interviews. As one person put it, "The canal has its own system. If you throw a dead donkey in the canal, it will be bones in a week." Individuals encounter potentially contaminated soil and water daily because of occupation, traditional behavior, or leisure. The river and canals afford water for fishing, recreation, irrigation and household chores, such as dish or clothes washing. These same water sources may also serve as disposal sites for biotic and abiotic refuse and as impromptu, or in some areas, regular sewage collectors. Petrol/diesel driven pumps, as well as, traditional water wheels/buckets, lift water into tanks and smaller irrigation channels where barefooted or sandaled farmers and children work. Domestic animals and wild birds also contribute to water and soil pollution. Wherever Egyptians live, one frequently finds small household, rooftop, or backyard domestic flocks of chickens, ducks, pigeons, and occasionally turkeys. In summary, two processes make the transfer of the H5N1 to domestic poultry possible: (1) direct virus transfer from wild birds/ducks to domestic fowl, and (2) primary or incidental virus transfer to the household, principally through routine daily human activities in the endemically infected natural environment. 


\subsubsection{The built environment}

Another recurring theme that emerged from data analysis reveals that the built environment facilitates virus transfer in several ways. Used here, the term built environment refers to that which "... comprises urban design, land use, and the transportation system and that encompasses human activity within the physical environment" [19, p.65]. Most H5N1 dispersion (estimated 78\%) appears to have been through human action rather than natural biotic action [20]. Egypt is a country of people on the move: by water, on foot, and by bicycle, car, train, donkey, donkey cart, motorbike, bus, or camel. Movement of poultry, poultry products, and infected materials contributes to the inadvertent spread of H5N1throughout the country $[21,22]$.

Egyptian policy makers initially focused on commercial producers, live markets, and macro-economic concerns following H5N1 identification in the country. In doing this, they failed to take into account customary practices and traditional exposure routes among small producers and average citizens. Both actions led to large-scale biosecurity lapses at the onset of the virus, which allowed the virus to go endemic. Subsequently, the free poultry vaccine program failed for two main reasons: (1) vaccine was ineffective [23] and (2) inadequate bio-security training of field technicians contributed to virus transference [24]. Securing perimeters, culling, and disinfecting major commercial farms proved easier than controlling the movement of traditional (backyard and household) producers' poultry. Upon learning of the government's culling initiatives, Egypt's small producers sought to save their flocks and their wealth by hiding or moving birds away from the of government's reach. When asked about children carrying roosters/chickens under their arms, one interviewee commented, "If it had feathers, the police killed it.....but when they came here people hid their chickens under the bed or took them to a relative's house so they wouldn't be killed". These actions effectively thwarted government efforts to geographically isolate and eliminate the virus, which ultimately resulted in it becoming endemic in 2008 [25].

Rurality figures significantly in human exposure to H5N1. First, interviewees stated that they raise poultry mainly for personal consumption as eggs and meat, with some local marketing. This substantiates observations reported previously [26]. Second, women usually tend household flocks kept in yards, cages, on rooftops, or in secured areas around courtyards of their homes, though children frequently carry poultry from place to place. Third, household poultry flocks are more common among rural households than urban ones. Fourth, rural built environments tend to be less sophisticated than urban areas and have more undeveloped areas scattered with garbage and animal litter, including poultry litter. Finally, officials find it more difficult to enforce regulations in rural areas.

\subsubsection{Sociopolitical and economic environments}

Data identified three principal sociopolitical/economic themes associated with bird flu: relative status, lack of reciprocal social capital, and consumer protein consumption. Raising poultry provides a source of great pride among Egyptian women. It not only increases her relative social status among peers, but also, represents relative economic power for the owner and her household. 
Intergenerational relationships, housing structure, and flock size contributed to deference behavior observed among households visited. Sale of excess poultry and eggs also increase a woman's economic independence. One woman stated, "I don't have to buy many eggs because I have my chickens." Therefore, owning poultry also provides a method adding protein to the diet through eggs and occasionally meat while elevating a woman's social status vis-à-vis her peers and relatives.

Reciprocal trust has been noted to be an important ingredient in development of rural social capital, $[27,28]$ and has been identified as a significant social determinant of health [29]. Rural Egyptian women distrust the government, government programs, and fear government will take actions against them and their poultry. Women do not trust the government to tell them the truth about the disease through the use of television, radio, or public service announcements (PSA's) to educate them about the disease. However, our results substantiate previous reports that women are aware of the bird flu [30]. Translating governmental information into daily life poses difficulty because rural women are not sure $\mathrm{H} 5 \mathrm{~N} 1$ constitutes a serious health threat to them since their birds are healthy. In addition, the fact that less attention to the topic appears in the news leads them to believe it either never existed or no longer poses a threat. Women expressed doubts that government actions to eradicate the disease are in their best interests, and, they frequently stated that the government is trying to take away their income in favor of large commercial enterprises. Some interviewees thought outside sources were responsible for trying to ruin the poultry industry, e.g., "Bird flu came from chicks imported from Turkey".

Bird flu has affected the diet and nutrition of average citizens as well as the macro-economy of Egypt. Before H5N1, the Egyptian poultry industry represented a LE (Egyptian pounds) 17 billion national investment, employed an estimated two-three million people either directly or indirectly, and accounted for 45 to 50 percent of animal protein consumed in Egypt, as compared to about 20 percent elsewhere in the world [31]. H5N1 resulted in the collapse of the Egyptian poultry industry $[32,33]$. As a result, the price of available fresh and frozen chicken rose approximately 500\% between 2006 and 2008 .

Consumer preferences play a role in continuation of relatively invisible live markets. Egyptians strongly prefer live birds slaughtered at sale to consumers [26]. "The frozen chickens that we get now do not taste right," one participant reflected. Although the government outlawed live bird markets, these markets continue to operate in spite of legal restrictions [34]. Live poultry continues to be available throughout Egypt, more so in rural areas, and can be purchased in live bird markets although these markets are rarely visible [35].

\subsubsection{Cultural environment}

Various facets of the cultural environment affect human exposure to bird flu; however, this research will focus on two main themes: women's awareness and knowledge of bird flu and behavioral risk factors. Everyone we encountered had heard of bird flu. Women acquire much of their knowledge about bird flu from their personal social network, which revolves around intergenerational, informal 
communication among women in the village or household. They also cited physicians, medical centers, and family planning clinics as health information sources. Women demonstrated a low level of personal empowerment regarding bird flu knowledge, voicing concern over information gaps about causation, transmission, procedures, and extent of the disease threat. As one informant asked, "How will I know if my chickens are sick?" Another stated, "I don't know who to call if my birds get sick". Discussions revealed that women had little or no understanding of bird flu etiology. When asked, "How do you think people get bird flu?" Answers ranged from "I don't know" to "handling sick chickens" to "handling wild or sick birds".

Community social workers conducted health education interventions targeting avian influenza throughout much of the country, including the study village. Interviewees cited washing hands, surfaces, and butchered birds as important for hygiene, but this was not new behavior stimulated by health education training. Village women appear to have selectively implemented prevention strategies into behavior change. It is not clear if they would implement prevention strategies in the presence of an immediate perceived risk such as sick birds in the area. For example, when displaying poultry sites, women did not change clothes, don gloves, cover their faces, or wear shoes when entering poultry pens or picking up poultry, although each of these practices were recommended in community based training. In addition, a single enclosure frequently housed chickens and ducks (although some were separated by wired dividers). One interviewee stated she did not understand how her ducks could give chickens bird flu. This perception is particularly problematic since ducks are asymptomatic when infected; yet, ducks shed more H5N1 virus than chickens when infected.

Proximal distance between people and poultry constitutes an important behavioral risk factor. When examining this particular risk factor, it is important to distinguish between primary and incidental direct virus exposure routes. The most direct primary exposure routes include handling infected birds, slaughtering/butchering, or food preparation. However, it is important that the virus also transfers from feces, feathers, and saliva to such items as bedding straw or soil on vehicles, equipment, cages, shoes, and clothes, providing an incidental direct exposure route. With the exception of a few roosters walking on the village streets, women we interviewed separated their poultry in small rooms, pens, or roof enclosures. It is not clear if this is new behavior or their tradition; however, this practice does reduce primary exposure opportunities to those in closest contact with enclosed poultry. However, many women do not always practice poultry isolation in spite of government educational efforts. For example, some women keep poultry in the yard during the day, but pen them over night, and some women allow poultry into the house, whereas, other do not.

Proximal distance between humans and poultry varies by age and sex in patterns similar to the disease occurrence. All ages and both sexes encounter incidental virus contaminated features of the environment. In the household environment, men may have infrequent direct contact with poultry, but commonly have incidental exposure at other venues. Women, who care for, 
slaughter/butcher poultry, dispose of remains, clean contaminated areas, and cook poultry experience primary exposure risks.

Slaughtering/butchering/food preparation practices provide the most obvious primary behavior risks when the virus is present. The level of risk varies depending on where and how birds are prepared, and, of course, if the birds are infected. For example, it is easiest to de-feather birds after dipping them into boiling water, but not all women have hot water where they slaughter/butcher birds. In fact, some women dry-pluck dead birds; however, the frequency and effect of virus dispersion of this practice is not known and should be assessed. Following slaughtering/butchering of the bird in a bucket, women typically clean the bucket and area with regular soap or detergent and wash/boil the poultry for cooking. After learning about bird flu, village women indicate they do not allow children with them when they slaughter poultry and that slaughtering occurs more often on the roof or outside the house rather than in the kitchen. This needs to be verified by extensive observation.

Other practices that accompany slaughtering/butchering/food preparation activities afford both primary and incidental exposure routes. Until H5N1, women could process and eat or freeze sick or dead poultry to avoid waste, prevent further loss of assets, and to prevent sickness in other birds. However, $\mathrm{H} 5 \mathrm{~N} 1$ infected poultry can contaminate freezers, other frozen products, and any surfaces with which it comes in contact. The extent of this practice needs further investigation. Next, the slaughter/butcher bucket is rarely a single purpose container, e.g., women use it for washing dishes and clothes or for cooking. Depending on where slaughter/butcher practices occurs, other uses for the space include cooking, sitting, visiting, children's play, or sleeping. Also, disposal of bird remains into the trash, street, or canals represents other behavior risks for incidental virus transfer. Furthermore, tucking the end of a hijab or headscarf over the face, suggested by training materials, will not likely eliminate virus inhalation. However, the practice would potentially contaminate more cloth surfaces. To suggest that women maintain separate clothing for tending poultry is unrealistic considering the poverty level in rural communities. Furthermore, since they may have only one or two daily-wear galabeas, it is unlikely women change clothing, put on special shoes, or even wear gloves or plastic bags on their hands (which may be bulky and cumbersome) while going about their daily poultry duties. When the virus is present, women's clothing, shoes, hair, preparation environment, and furniture provide incidental exposure routes or potential transfer mechanisms for the virus to other parts of the environment.

Children's behavior presents a special case, because their behavior presents both primary and incidental virus transfer opportunities. Enclosing poultry away from living quarters may limit, but not eliminate, childhood exposure. Furthermore, children often assist in tending to poultry, especially chickens and ducks. Older children often develop an "owner-pet" affiliation with their poultry carrying them about with them from place to place in the village. Older children also participate in child-care activities for their younger siblings and relatives. Early childhood exposure risks are not limited to being in close proximity to persons who may have the virus on their clothing, hair, hands, or feet, but also 
contaminated accessible household surfaces, both indoors and out, e.g., preparation tables, floors, furniture, and other surfaces that are not easily decontaminated. Small children and babies accompany their elders throughout the day. Like children everywhere, small children also crawl and walk about the home, often without shoes; climb on furniture; and, put hands and items in their mouths. Finally, older children or adults almost constantly hold babies and small children, a loving action that can be risky if the person holding the child has the $\mathrm{H} 5 \mathrm{~N} 1$ virus on their person.

\section{Conclusions}

Poultry flocks represent a source of income and nutrition for families living in rural Egypt. Importantly, poultry also represents a prestige value, i.e., a source of pride and status to families. H5N1 easily transfers through bio-security lapses across borders and even from house to house. Our results suggest that the disparate incidence and mortality pattern of H5N1 in Egypt is likely affected by increased exposure opportunities among women and children resulting from lack of knowledge, traditional daily activities, poultry practices, and child-rearing activities.

Despite community based health education efforts, Egyptian women do not know or understand enough about poultry diseases and H5N1 transmission. In the absence of a perceived immediate bird flu threat, this research suggests that women tend to maintain traditional behavioral patterns they learned from their mothers and grandmothers when they were children. Similarly, they pass this knowledge along to their children through their behavior. The majority of women at risk are in the preconception stage of change according to the Transtheoretical Model of Health Behavior [36] , and, thus, do not recognize a need to change their risky behaviors. Therefore, it is suggested that future health education interventions initially focus on consciousness-raising and selfreevaluation associated with $\mathrm{H} 5 \mathrm{~N} 1$ among this population.

The observed value rural Egyptian women place on raising household, yard, and roof poultry may well be representative of the practice in communities and countries yet unaffected by the H5N1 virus. Therefore, the authors believe the model presented provides a starting point for assessing $\mathrm{H} 5 \mathrm{~N} 1$ in other geographical and cultural settings. Finally, the H5N1 epidemiologic footprint in Egypt may be different from other countries, but the lessons learned provide a basis for health education action and which may be transferable to other countries and diseases.

\section{References}

[1] World Health Organization. Epidemic and pandemic alert and response (EPR): Avian Influenza. Online. http://www.who.int/csr/disease/ avian_influenza/en/

[2] Zhou L, Liao Q, Dong L, Huai Y, Bai T, Xiang N, et al. Risk factors for human illness with avian influenza A (H5N1) virus infection in China. The Journal of Infectious Diseases, 199(12), pp. 1726-1734. 2009. 
[3] Dudley J. Age-specific infection and death rates for human A (H5N1) avian influenza in Egypt. Euro surveillance, 14(18), pp. 1-2, 2009.

[4] Fasina F, Ifende V, Ajibade A. Avian influenza A (H5N1) in humans: lessons from Egypt. Euro surveillance, 15(4), pp. 1-4, 2010.

[5] Kandeel A, Manoncourt S, elKareem EA, Ahmed A-NM, El-Refaie S, Essmat $\mathrm{H}$, et al. Zoonotic transmission of avian influenza virus (H5N1), Egypt, 2006-2009. Emerging Infectious Diseases, 16(7), 2010. Online. http://www.cdc.gov/EID/content/16/7/1101.htm

[6] Vayda A. Progressive contextualization: Methods for research in human ecology. Human Ecology, 11(3):265-81, 1983.

[7] McLeroy KR, Bibeau D, Steckler A, Glanz K. An ecological perspective on health promotion programs. Health Education \& Behavior, 15(4), pp. 351377, 1988.

[8] Barbosa CS. Epidemiology and Anthropology: an integrated approach dealing with bio-socio-cultural aspects as strategy for the control of endemic diseases. Memórias do Instituto Oswaldo Cruz, 93, pp. 59-62, 1998.

[9] Reifsnider E, Gallagher M, Forgione B. Using ecological models in research on health disparities. Journal of Professional Nursing, 21(4), pp. 216-222, 2005.

[10] McElroy A, Townsend P. Medical Anthropology in Ecological Perspective. Boulder, CO. 5th ed: Westview Press, 2008.

[11] Scott A, Wilson R, Scott A. Social determinants of health among African Americans in a rural community in the Deep South: an ecological exploration. Rural and Remote Health, 11, No. 1634, 2011. Online. http://www.rrh.org.au

[12] Van Maanen J. Ethnography then and now. Qualitative Research in Organizations and Management: An International Journal, 1(1), pp. 13-21, 2006.

[13] Birks M, Chapman Y, Francis K. Memoing in qualitative research. Journal of Research in Nursing, 13(1), pp. 68-75, 2008.

[14] Strauss A, Corbin J. Basics of qualitative research: Grounded theory procedures and techniques. Sage publications: Newbury Park, CA, 1990.

[15] Thomas DR. A general inductive approach for analyzing qualitative evaluation data. American Journal of Evaluation, 27(2), pp. 237-246, 2006.

[16] Iaquinta D, Drescher A. Defining the peri-urban: rural-urban linkages and institutional connections. Land Reform, Land Settlement and Cooperative, 2000(2), pp. 8-26, 2000.

[17] El-Zanaty F, Way A. Egypt demographic and health survey 2005. Cairo, Egypt: Ministry of Health and Population, National Population Council, ElZanaty and Associates, and ORC Macro, pp. 377, 2006.

[18] Williams R, Peterson A. Ecology and geography of avian influenza(HPAI $\mathrm{H} 5 \mathrm{~N}$ 1) transmission in the Middle East and northeastern Africa. International Journal of Health Geographics, 8(47), pp. 1-11, 2009. 
[19] Handy SL, Boarnet MG, Ewing R, Killingsworth RE. How the built environment affects physical activity. American Journal of Preventive Medicine, 23(2S), pp. 64-73, 2002.

[20] Kaoud HA. HPAI Epidemic in Egypt: Evaluation, Risk Factors and Dynamic of Spreading. International Journal of Poultry Science, 6(12), pp.983-988,2007.

[21] Food and Agriculture Organization. Questions \& Answers: The Facts of Bird Flu. Online. http://www.fao.org/avianflu/en/qanda.html.

[22] World Health Organization, International Food Safety Authorities Network (INFOSAN). Highly pathogenic H5N1 avian influenza outbreaks in poultry and in humans: Food safety implications, 2005. Online. www.who.int/foodsafety/fs_management/No_07_AI_Nov05_en.pdf

[23] Hafez MH, Arafa A, Abdelwhab EM, Selim A, Khoulosy SĞ, Hassan MK, et al. Avian influenza H5N1 virus infections in vaccinated commercial and backyard poultry in Egypt. Poultry Science, 89(8), pp.1609-1613, 2010.

[24] Peyre M, Samaha H, Makonnen YJ, Saad A, Adbd-Einabi A, Galal S, et al. Avian influenza vaccination in Egypt: Limitations of the current strategy. Journal of Molecular and Genetic Medicine,v3(2), pp. 198-204, 2009.

[25] World Organization for Animal Health. Update on highly pathogenic avian influenza in animals (Type $\mathrm{H} 5$ and $\mathrm{H} 7$ ). Online. http://www.oie.int/downld/AVIAN\%20INFLUENZA/A_AI-Asia.htm.

[26] Taha FA. The Poultry Sector in Middle-Income Countgries and Its Fee Requirements: The case of Egypt, United States Department of Agriculture, 2003.

[27] Putnam RD, Leonardi R, Nanetti R. Making Democracy Work: Civic Traditions in Modern Italy, Princeton University Press, 1994.

[28] Falk I, Kilpatrick S. What is social capital? A study of interaction in a rural community. Sociologia Ruralis, 40(1), pp. 87-110, 2000.

[29] Scott AJ, Wilson R, Scott A. Social determinants of health among African Americans in a rural community in the Deep South: an ecological exploration. Rural and Remote Health. 11(1634), pp. 1-12, 2011.

[30] El-Zanaty F, El-Ghazaly N. Final Study Report: Avian Influenza Household Survey: Knowledge, Attitudes and Practices of the Egyptian Public. Report. Cairo, Egypt: UNICEF, Egypt, 2007.

[31] Leila R. Poultry industry collapses. Al-Ahram Weekly, 23 Feb-1 March, 2006.

[32] GRAIN. Bird flu crisis small farms are the solution not the problem. Seedling. 2006. Online. http://www.grain.org/seedling/?id=437\#

[33] Khattab A. A Foul Business. Egypt Today. 2006. Online. http://www.egypttoday.com/article.aspx?ArticleID=6448

[34] SAIDR. Homepage. Cairo, Egypt. 2010. Online. http://www.saidr.org/.

[35] Sparks V. Personal Communication, 8 July 2010, Social Science Division, Brookhaven College, Dallas, TX, USA.

[36] Rosenstock I. The health belief model: Explaining health behavior through expectancies. Health Behavior and Health Education, eds. K. Glanz, B. Rimer, \& F. Lewis. Jossey-Bass: San Francisco, pp. 39-62: 1990. 